\title{
High Levels of Outcrossing in a Family Trial of Western Australian Sandalwood (Santalum spicatum)
}

\author{
By K. Murr ${ }^{1)}$, M. Byrne ${ }^{2, *)}$, E. Barbour ${ }^{3)}$, M. C. Cox ${ }^{1)}$ and J. E. D. Fox ${ }^{1)}$
}

(Received 10 ${ }^{\text {th }}$ May 2006)

\begin{abstract}
The mating system of Western Australian sandalwood (Santalum spicatum) was investigated in seed collections from a family trial. The mean outcrossing rate was high $(95.2 \%)$ although there was variation among families and one family showed particularly low outcrossing, high bi-parental inbreeding and high correlated paternity. Variation in flowering time between this family and others in the trial was the most likely cause of the high inbreeding and low number of fathers contributing to the seed crop in trees from this family. The high level of outcrossing in the rest of the families indicated that $S$. spicatum has a preferentially outcrossed mating system, but that it is capable of selfing when conditions are unsuitable for outcrossing. The seedling progeny showed no influence of inbreeding on seedling height at 4 months. Analysis of genetic diversity revealed high levels of genetic diversity have been captured in the seed crop from the trial, and this diversity is comparable to that identified in a previous study of natural populations from throughout the range of the species. These results indicated that production of seed through seed orchards will be a successful means of deployment of breeding gains in the species, however it is essential to ensure overlap in flowering times among different families planted in a seed orchard.
\end{abstract}

Key words: Sandalwood, mating system, outcrossing, pollen dispersal.

\section{Introduction}

Sandalwood is the fragrant heartwood of the stem and roots of some species of Santalum, a genus belonging to Santalaceae. The aromatic timber of sandalwood has been highly prized for many centuries, particularly in China, India and the Middle East, as it contains a sesquiterpene essential oil (ADAMs et al., 1975) that is mainly used in the perfume industry, but is also used for incense and joss stick manufacture and for carving (RAI, 1990). The majority of commercial sandalwood is obtained from Indian sandalwood (Santalum album) that is harvested from natural populations and plantations in India and Asia (SRINIVASAN et al., 1992). West-

1) Department of Environmental Biology, Curtin University of Technology, GPO Box U 1987, WA 6845, Australia.

2) Science Division, Department of Environment and Conservation, Locked Bag 104, Bentley Delivery Centre, WA 6983, Australia.

${ }^{3}$ ) Forest Products Commission, Locked Bag 888, Perth Business Centre, WA 6849, Australia.

*) Communicating author: M. ByrNe, Science Division, Department of Environment and Conservation, Locked Bag 104, Bentley Delivery Centre, WA 6983, Australia. Phone: +61-89334-0503, Fax: +61-8-9334-0327. E-mail: Margaret.Byrne@ dec.wa.gov.au ern Australian sandalwood (Santalum spicatum (R.Br.) A.DC.) produces aromatic wood similar to Indian sandalwood (ADAMs et al., 1975), and Western Australia is also a producer and exporter of sandalwood timber to several Asian countries where it is used mainly in the manufacture of joss sticks (JONES, 2001). Several other species of Santalum occur in Australia but they do not produce sufficient quantities of the sesquiterpenes that make up the sandalwood fragrance to be of commercially significance (SHEA et al., 1998). Santalum spicatum has been harvested commercially in Western Australia since 1845 and was a primary industry in the early years of European settlement (LONERAGAN, 1990).

Santalum spicatum occurs naturally throughout the semi-arid and arid regions of Western Australia, which are characterized by low rainfall, typically averaging between 150-500 mm annually (BoLAND et al., 1984). It is a slow growing root hemi-parasite tree (HEwson and GEORGE, 1984) that commonly occurs with nitrogen fixing plants such as Acacia or Allocasuarina that it uses as hosts (LONERAGAN, 1990). Western Australian sandalwood is sourced from natural populations but the abundance of the species has been reduced due to extensive harvesting combined with poor recruitment and slow growth. The use of this natural resource requires sustainable management including control of harvesting, successful regeneration through seed burial, and the reduction of feral grazing. The feasibility of commercial production of sandalwood from plantations in the agricultural areas of Western Australia is being investigated (SHEA et al., 1998) and research into silviculture, parasite-host relationships, oil production and breeding is being carried out (BRAND et al., 1999).

Santalum spicatum is found across a wide range of environmental conditions and exhibits a degree of morphological variation that suggests the presence of two ecotypes within the species (Fox and BRAND, 1993). In the higher rainfall, semi-arid areas in the south the species has larger leaves and nuts, higher chlorophyll content and tends to have thicker stems than those in the arid areas in the north of the distribution (Fox and BRAND, 1993). Trees in the arid areas have a higher concentration of oil in the wood than trees from the semiarid areas (LONERAGAN, 1990). The morphological variation probably reflects some adaptation to environmental conditions but also reflects a genetic component, as genetic differentiation occurs between populations in the arid and semi-arid regions (BYRNE et al., 2003). Variation in growth rates among families from both regions has also been observed in a field trial (BRAND et al., 1999) indicating some genetic influence on growth characteristics. 
Domestication and development of improvement programs are enhanced by knowledge of the genetic structure of species, which enables a broad representation of genetic diversity to be introduced to breeding populations and seed orchards (MorAN et al., 2000). Genetic analysis of the species has shown moderate levels of diversity and genetic differentiation between populations in the semi-arid versus arid regions (BYRNE et al., 2003) suggesting that collections of germplasm for plantations in the semi-arid region should be made from populations within this region and not from populations in the arid zone. Some populations within the semi-arid region exhibit significant genetic differences, and therefore collection strategies should include a range of populations to capture a broad representation of the genetic diversity present in the region.

The design, establishment and monitoring of seed orchards are assisted by knowledge of a range of factors involved in the breeding system of a species. Pollination biology, outcrossing rate, pollen dispersal and pollination neighbourhood size all influence the functioning of a seed orchard. These factors are being investigated as part of the breeding program of S. spicatum, to assist in the development and optimal performance of seed orchards. Like other Santalum species, S. spicatum exhibits mass flowering, has small, insect-pollinated flowers and low seed set (BARRETT, 1987).

Examination of pollen tube development in S. spicatum and $S$. album has shown the presence of pollen tubes in the style and ovary but a lack of penetration of embryo sacs following self-pollination (RUGKHLA et al., 1997). Also, crossing experiments on S. spicatum and $S$. album resulted in no seed set or the development of seed without embryos following self-pollination, while cross-pollination resulted in the formation of viable seed (RUGKHLA et al., 1997; McComb and JoNES, 1998). Similar studies on $S$. album also documented seed set following cross-pollination but not following self-pollination (BADAMI and VENKATA RAO, 1930; MuniYAPPA et al., 1980; Kulkarni and MuniYamma, 1997). However, Sindhu VeEREndRa and Sujatha (1989) and Sindhu Veerendra and ANANTha PADMANabHa (1996) reported seed set following self-pollination in $S$. album.

In this study, the mating system of $S$. spicatum was investigated in an establishment trial using co-dominant genetic markers to determine outcrossing rate. Nuclear restriction fragment length polymorphism (RFLP) markers have been developed and shown to be informative in assessing diversity (BYRNE et al., 2003). A previous study (BRAND, 1993) showed isozyme markers to be inadequate for analysis of genetic variation in $S$ spicatum and, as microsatellite markers were not available at the time of this study (although they have been developed subsequently in S. austrocaledonicum (BotTin et al., 2005)), RFLP markers were used.

\section{Methods}

\section{Sampling strategy}

This study was conducted using trees in a S. spicatum trial at Narrogin, Western Australia. The trial was planted in 1998 as an establishment trial with S. spicatum seed from six trees, one tree from each of six geographically dispersed provenances, and with Acacia acuminata as the host species (planted in 1997). Trees in the trial flowered in 2001 and at the time of sampling for this study in late 2003 it was the only trial of flowering age where the family identity and source of the trees was known. Although the genetic base of the trial is limited to progeny from only one tree per provenance, it does provide for investigation of the effects of mating between close relatives (mother trees from the same family are half sibs) verses mating between unrelated plants (mother trees from different provenances), such as might be encountered in a seed orchard situation. The trial has 360 trees in total in six replicate block plantings. For this study, 20 seeds were collected from three trees of each family from one replicate. Seed was germinated in individual pots following a 16-hour pretreatment with gibberellic acid (GA3). The height of each seedling was measured four months after sowing, and at the same time approximately $10 \mathrm{~g}$ of leaf material was collected from the seedlings for DNA extraction. Leaf material was also collected from the mother plants in the trial and used to determine the maternal genotype.

\section{RFLP procedure}

DNA was extracted from approximately $9 \mathrm{~g}$ of fresh leaf material using a modified CTAB procedure (BYRNE, 1999), except that yellow globules that formed in the aqueous phase after chloroform extraction were removed. The removal of these globules resulted in greater yield and purity than had previously been obtained. For each sample $3 \mu \mathrm{g}$ of DNA was digested with the restriction enzyme EcoR V, subjected to electrophoresis, Southern-blotted and hybridized with seven probes (S38, S47, S51, S62, S77, S83 and S93). These had been developed previously from a genomic library of S. spicatum and were known to detect single loci (BYRNE et al., 2003). Hybridization and restriction digestion conditions were as described in BYRNE and MORAN (1994). Probe plasmids were labeled with ${ }^{32} \mathrm{P}$ using the random priming method.

\section{Data analysis}

Bands on the autoradiographs were scored according to their molecular weight and interpreted as co-dominant alleles at loci. Genotypes of the maternal tree and the seedling progeny were scored and direct determination of selfed and outcrossed progeny was made by comparison of the progeny genotype to the maternal genotype. Progeny with a non-maternal allele were identified as resulting from an outcrossed mating event. The multilocus mating system program, MLTR V2.4 (RITLAND, 2002), was utilized to identify the rate of out-crossing, level of biparental inbreeding and correlated paternity, female and male gene frequencies and the correlation of out-crossed paternity within progeny arrays. Differentiation between the pollen pools of each mother tree was investigated using the TWOGENER analysis of SMOUSE et al. (2001) based on the AMOVA approach of ExCOFFIER et al. (1992) as implemented in the GENER program 
(DYER, 2005). Seedling height data were analysed using a one-way ANOVA and treatment means for significant values were compared using Tukey's multiple comparison test conducted using SPSS version 11.

Genetic diversity parameters, polymorphic loci, observed heterozygosity, expected heterozygosity, and the partitioning of variation were analyzed using the population genetics software program GenAlEx V5 (PEAKall and Smouse, 2001). The relationship between individuals was evaluated using a Principal Co-ordinates Analysis (PCA) based on calculation of genetic distance between individuals as described by PEAKALL et al. (1995). The data were analysed at both the individual mother tree and family level. The genetic diversity parameters of the progeny were compared with genetic diversity parameters obtained in a previous study of 23 natural populations across the range (BYRNE et al., 2003). The diversity parameters of the natural populations were recalculated for the seven loci used in this study. The partitioning of variation (AMOVA) between the planted trial and the natural populations was determined using GenAlEx V5.

\section{Results}

Mating system analysis

Data was derived from 210 progeny individuals from the 18 mother trees ( 3 mother trees $\times 6$ families) as some seeds failed to germinate or didn't survive to 4 months. Progeny arrays ranged from 9 to 20 seedlings but most had between 10 and 15 progeny per family. The direct determination of outcrossing rate ranged from $30 \%$ (Mother tree 9) to 100\% (Mother tree 13) with a mean of $73.9 \%$ (Table 1 ). Outcrossing rates were generally similar among mother trees within families but there was large variance among families where mean outcrossing rates ranged from 37.5 (Family 3 ) to $94.2 \%$ (Family 5).

Mating system parameters of the $S$. spicatum progeny at the family level calculated using the mixed mating

Table 1. - Mating system parameters for Santalum spicatum trees in the Narrogin trial. $t m$, multi-locus out-crossing rate; $t m$-ts, biparental inbreeding; $r p$, correlated paternity; standard error in parentheses.

\begin{tabular}{|c|c|c|c|c|}
\hline $\begin{array}{l}\text { Mother tree }(\mathrm{M}) / \\
\text { Family }(\mathrm{F})\end{array}$ & $\begin{array}{c}\text { Direct } \\
\text { estimation of } \\
\text { out-crossed } \\
\text { progeny }(\%)\end{array}$ & $t m$ & $t m-t s$ & $r p$ \\
\hline M1 & 70.0 & & & \\
\hline M2 & 80.0 & & & \\
\hline M3 & 90.0 & & & \\
\hline F 1 (Mean) & 80 & $0.878(0.214)$ & $0.122(0.075)$ & $0.160(0.088)$ \\
\hline M4 & 90.0 & & & \\
\hline M5 & 70.0 & & & \\
\hline M6 & 90.0 & & & \\
\hline F 2 (Mean) & 83 & $0.942(0.152)$ & $0.010(0.144)$ & $0.133(0.064)$ \\
\hline M7 & 46.0 & & & \\
\hline M8 & 40.0 & & & \\
\hline M9 & 30.0 & & & \\
\hline F 3 (Mean) & 37.5 & $0.409(0.104)$ & $0.151(0.052)$ & $0.585(0.414)$ \\
\hline M10 & 41.6 & & & \\
\hline M11 & 60.0 & & & \\
\hline M12 & 76.9 & & & \\
\hline F 4 (Mean) & 60 & $0.726(0.195)$ & $0.176(0.068)$ & $0.418(0.297)$ \\
\hline M13 & 100.0 & & & \\
\hline M14 & 88.8 & & & \\
\hline M15 & 91.6 & & & \\
\hline F 5 (Mean) & 94.2 & $1.200(0.325)$ & $0.396(0.112)$ & $0.058(0.050)$ \\
\hline M16 & 86.6 & & & \\
\hline M17 & 90.0 & & & \\
\hline M18 & 90.0 & & & \\
\hline F 6 (Mean) & 88.6 & $1.156(0.235)$ & $0.325(0.152)$ & $-0.003(0.074)$ \\
\hline Mean for Families & 73.9 & 0.885 & 0.197 & 0.225 \\
\hline
\end{tabular}


model of RiTLAND (2002), are given in Table 1. The mean multi-locus out-crossing rate $(\mathrm{tm})$ for the families was high with a mean value of 0.885 . Family 3 had the lowest out-crossing rate $(0.409)$ while Family 5 had the highest (1.200). The outcrossing rates were high and similar among Families 1, 2, 5 and 6, but Families 3 and 4 both had much lower values. All mother trees within Family 3 exhibited low outcrossing rates, whereas in Family 4 only one mother tree had a particularly low outcrossing rate. The biparental inbreeding rate $(\mathrm{tm}$ - $\mathrm{ts})$ varied across families with a mean of 0.197 and a range of 0.010 (Family 2) to 0.396 (Family 5). Biparental inbreeding was low to moderate in Families 1, 2, 3 and 4 but high in Families 5 and 6 . The mean correlated paternity $(r p)$ was also generally low to moderate with a mean of 0.225 and a range of -0.003 (Family 6 ) to 0.585 (Family 3). Low correlated paternity values were observed in Families 5 and 6, moderate values in Families 1 and 2 and high values in Families 3 and 4 .

\section{Pollen pool differentiation}

The level of pollen pool differentiation across all sampled mother trees was high as the global $\Phi_{\mathrm{ft}}$ was 0.193 (0.142). However, there was a large variation in the pairwise differentiation among mothers, ranging from $-0.078(-0.032)$ to $0.489(0.429)$. Analysis of pairwise differentiation between mothers allowed further refinement of the patterns of pollination among mothers and families. The pairwise pollen pool differentiation between all pairs of mothers in combinations of families is shown in Table 2. The pollen pool differentiation between mothers within Families 1, 2, 5 and 6 was low (average 0.067) compared to those of Families 3 and 4 (average pairwise $\Phi_{\mathrm{FT}}=0.368$ and 0.255 respectively).
The average pairwise pollen pool differentiation between all mothers in Families 1, 2, 5 and 6 was 0.101 which was much lower than the differentiation between mothers in Families 3 and 4 with all other mothers (average pairwise $\Phi_{\mathrm{FT}}=0.289$ and 0.245 respectively).

Selfing leads to increased pollen pool heterogeneity (Austerlitz and SMouse, 2001a), and this may be influencing the high heterogeneity in Families 3 and 4, therefore the selfed progeny were removed from the data set and the pollen pool differentiation recalculated. As expected, removal of selfed progeny reduced pollen pool heterogeneity within Families 3 (0.249) and 4 (0.151), and reduced the pairwise differentiation between mother trees in Families 3 and 4 and all other mother trees (0.193 and 0.175 respectively). However, the level of pollen pool differentiation was still high indicating dissimilarity in pollen pools of mother trees from Families 3 and 4 compared to those of the other families. Removal of selfed progeny had little effect on the pollen pool differentiation within and between Families $1,2,5$ and 6 (average within families 0.069, average pairwise differentiation among all mother trees 0.101).

\section{Seedling height}

Seedling heights 4 months after sowing are presented in Table 3. The mean height of seedlings from different families ranged from 92 to $121 \mathrm{~mm}$. There was a significant difference $(p=0.036)$ between the mean height for Family 2 (the largest) and Family 6 (the smallest) but not between the mean heights of the other families. The mean heights of seedlings from the two families that displayed inbreeding within the progeny (Families 3 and 4) did not differ from those families displaying outcrossing within the progeny.

Table 2. - Differentiation in sampled pollen pools among mother trees from families of Santalum spicatum in the Narrogin trial. Values represent average pairwise $\Phi_{\mathrm{FT}}$ between all mother trees in each family combination.

\begin{tabular}{|l|l|l|l|l|l|l|}
\hline & Family 1 & Family 2 & Family 3 & Family 4 & Family 5 & Family 6 \\
\hline Family 1 & 0.099 & & & & & \\
\hline Family 2 & 0.186 & 0.067 & & & & \\
\hline Family 3 & 0.329 & 0.303 & 0.368 & & & \\
\hline Family 4 & 0.266 & 0.258 & 0.305 & 0.255 & & \\
\hline Family 5 & 0.126 & 0.044 & 0.291 & 0.232 & 0.034 & \\
\hline Family 6 & 0.154 & 0.103 & 0.217 & 0.165 & 0.104 & 0.071 \\
\hline
\end{tabular}

Table 3. - Mean height of seedlings of Santalum spicatum grown from seed collected from different families in the Narrogin trial. Height measured at 4 months after sowing. N, number of seedlings. Standard error in parentheses. Letters indicate significant differences among families $(\mathrm{p}<0.05)$. Mating system based on outcrossing rate determined in this study.

\begin{tabular}{ccccc}
\hline Family & N & Height $(\mathrm{mm})$ & Significance & Mating system \\
\hline 2 & 31 & $121(7.83)$ & $\mathrm{a}$ & outcrossed \\
4 & 40 & $118(7.86)$ & $\mathrm{ab}$ & outcrossed/inbred \\
3 & 33 & $115(6.29)$ & $\mathrm{ab}$ & inbred \\
5 & 32 & $114(7.72)$ & $\mathrm{ab}$ & outcrossed \\
1 & 33 & $109(6.96)$ & $\mathrm{ab}$ & outcrossed \\
6 & 35 & $92(5.35)$ & $\mathrm{b}$ & outcrossed \\
\hline
\end{tabular}




\section{Genetic diversity measures}

Genetic diversity parameters were calculated based on the genotypes of the 18 mother trees used in the study. Polymorphism was high across all loci with a total of 89 alleles. The mean proportion of polymorphic loci was $78.6 \%$. The number of alleles identified at a locus ranged from 1 to 4 with an average of 2.11 . This sample of 18 trees displayed a moderate number of alleles per locus $\left(\mathrm{n}_{\mathrm{a}}=2.33\right)$ but high observed heterozygosity $\left(H_{o}=\right.$ $0.56)$.

Genetic diversity parameters for the progeny of each mother tree were calculated based on the progeny genotypes. Polymorphism was high across all loci with a total of 53 alleles and only progeny from one mother tree was monomorphic (Mother tree 8, Family 3). Among progeny from the 18 mother trees the mean proportion of polymorphic loci was $90.5 \%$ and the number of alleles identified at a locus ranged from 3 to 6 with a mean of 4.7. The maximum number of alleles at a locus in any one progeny set was 6 . The values for the mean number of alleles per locus $\left(\mathrm{n}_{\mathrm{a}}\right)$, observed heterozygosity $\left(H_{o}\right)$ and the Hardy-Weinberg expected panmictic heterozygosity
$\left(H_{e}\right)$ were moderate for each mother tree progeny (Table 4 ). The number of alleles ranged from 1.86 (Mother trees 8 and 9) to 3.86 (Mother tree 13). Observed heterozygosity ranged from 0.27 (Mother tree 4) to 0.55 (Mother tree 13) while expected heterozygosity ranged from 0.23 (Mother tree 4) to 0.48 (Mother tree 16).

Analysis of the partitioning of variation showed the majority of variation within families $(75 \%)$ with $25 \%$ of variation maintained among families, indicating some level of differentiation among the progeny from different families. The PCA of relationships among the progeny showed some spatial separation of progeny from some families (Figure 1). The majority of progeny from mother trees within families occupied the same ordination space, however, progeny from mother trees in Family 3 were separated along co-ordinate 1.

The genetic diversity values of the progeny obtained from the Narrogin trial were compared with results from a study of genetic diversity in natural populations across the range of S. spicatum (BYRNE et al., 2003). The genetic diversity of the natural populations was recalculated for the seven loci used in this study and the diver-

Table 4. - Genetic diversity parameters for mother trees of Santalum spicatum sampled from the Narrogin trial. $\mathrm{n}_{2}$, mean number of alleles per locus; $H_{o}$, observed heterozygosity; $H_{e}$, expected heterozygosity; standard error in parenthesis.

\begin{tabular}{|c|c|c|c|}
\hline $\begin{array}{c}\text { Mother tree }(\mathrm{M}) / \\
\text { Family }(\mathrm{F})\end{array}$ & $\mathrm{n}_{\mathrm{a}}$ & $H_{o}$ & $H_{e}$ \\
\hline M1 & $2.29(0.65)$ & $0.41(0.10)$ & $0.36(0.09)$ \\
\hline M2 & $2.43(0.67)$ & $0.39(0.09)$ & $0.37(0.07)$ \\
\hline M3 & $2.14(0.71)$ & $0.37(0.08)$ & $0.28(0.06)$ \\
\hline F 1 (Mean) & $2.29(0.67)$ & $0.39(0.09)$ & $0.34(0.07)$ \\
\hline M4 & $2.29(0.60)$ & $0.27(0.05)$ & $0.23(0.05)$ \\
\hline M5 & $3.00(0.63)$ & $0.52(0.11)$ & $0.43(0.10)$ \\
\hline M6 & $2.86(0.66)$ & $0.54(0.09)$ & $0.38(0.09)$ \\
\hline F 2 (Mean) & $2.71(0.63)$ & $0.44(0.08)$ & $0.35(0.08)$ \\
\hline M7 & $2.57(0.67)$ & $0.44(0.12)$ & $0.40(0.08)$ \\
\hline M8 & $1.86(0.59)$ & $0.28(0.04)$ & $0.25(0.06)$ \\
\hline M9 & $1.86(0.61)$ & $0.32(0.07)$ & $0.26(0.07)$ \\
\hline F 3 (Mean) & $2.09(0.62)$ & $0.35(0.07)$ & $0.30(0.07)$ \\
\hline M10 & $2.43(0.64)$ & $0.30(0.06)$ & $0.26(0.06)$ \\
\hline M11 & $2.71(0.72)$ & $0.37(0.08)$ & $0.32(0.08)$ \\
\hline M12 & $2.43(0.68)$ & $0.36(0.08)$ & $0.28(0.08)$ \\
\hline F 4 (Mean) & $2.52(0.68)$ & $0.34(0.07)$ & $0.29(0.07)$ \\
\hline M13 & $3.86(0.76)$ & $0.55(0.11)$ & $0.41(0.09)$ \\
\hline M14 & $2.57(0.67)$ & $0.41(0.09)$ & $0.35(0.08)$ \\
\hline M15 & $3.00(0.74)$ & $0.41(0.10)$ & $0.36(0.08)$ \\
\hline F 5 (Mean) & $2.80(0.72)$ & $0.45(0.10)$ & $0.37(0.08)$ \\
\hline M16 & $3.29(0.78)$ & $0.54(0.12)$ & $0.48(0.11)$ \\
\hline M17 & $2.71(0.63)$ & $0.44(0.09)$ & $0.38(0.09)$ \\
\hline M18 & $2.57(0.61)$ & $0.45(0.10)$ & $0.38(0.08)$ \\
\hline F 6 (Mean) & $2.85(0.67)$ & $0.48(0.10)$ & $0.41(0.09)$ \\
\hline Mean for Families & $2.54(0.66)$ & $0.40(0.08)$ & $0.34(0.07)$ \\
\hline
\end{tabular}




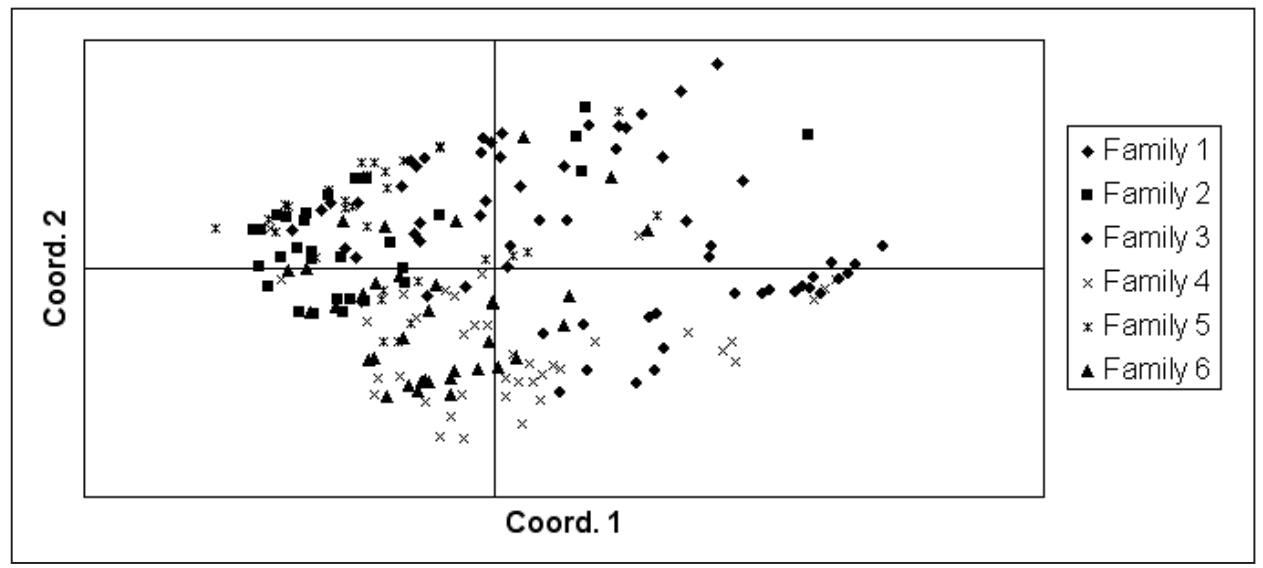

Figure 1. - Principal Co-ordinates Analysis of genetic diversity in Santalum spicatum progeny from the Narrogin trial. Symbols denote families.

Table 5. - Allelic diversity parameters for Santalum spicatum progeny from the Narrogin trial and for S. spicatum populations from natural stands (values for the natural populations from BYRNE et al., 2003a recalculated for the 7 loci used in this study). $\mathrm{n}_{\mathrm{a}}$, mean number of alleles per locus; $\mathrm{n}_{\mathrm{a}},>0.05$ mean number of alleles per locus with frequency $>0.05 ; H_{o}$, observed heterozygosity; $H_{e}$, expected heterozygosity.

\begin{tabular}{lcccc}
\hline Group & $\mathrm{n}_{\mathrm{a}}$ & $\mathrm{n}_{\mathrm{a}}>0.05$ & $H_{o}$ & $H_{e}$ \\
\hline Progeny from trial & 4.71 & 3.14 & 0.42 & 0.51 \\
Natural populations & 5.86 & 2.14 & 0.32 & 0.39 \\
\hline
\end{tabular}

sity values were similar to those observed in the Narrogin trial (Table 5). The mean number of alleles $\left(\mathrm{n}_{\mathrm{a}}\right)$ for the Narrogin trial progeny was lower than that for the natural populations, but the number of alleles with frequency $>0.05$ was higher. The progeny from the Narrogin trial had higher mean observed heterozygosity and gene diversity than the natural populations. An analysis of variance between the trial progeny and the natural populations gave $\Phi_{\mathrm{FT}}$ of 0.181 with a significance value of 0.01 .

\section{Discussion}

Results of the mating system analysis of S. spicatum revealed a high outcrossing rate, with most individual mother trees showing preferential outcrossing. However, particular mother trees from Family 3 (Mother trees 7, 8 and 9) and Family 4 (Mother tree 10) exhibited low levels of outcrossing, indicating that selfing is possible in $S$. spicatum. The mother trees from Family 3 all demonstrated a very low proportion of outcrossing, potentially indicating a high level of inbreeding in progeny originating from trees of this family. In contrast, while Family 4 displayed a low overall outcrossing rate, some variation in the rate was observed between mother trees (e.g. $76.9 \%$ of Mother tree 12 progeny were outcrossed).

Investigations of biparental inbreeding across the families revealed variable results. Families 5 and 6 displayed high biparental inbreeding and Families 3 and 4 displayed a moderate level. This indicates that a large proportion of the observed outcrossing in these families was breeding between related individuals. The proportion of correlated paternity was also found to be variable among the families. Low levels of correlated paternity were displayed by Families 5 and 6, signifying multiple paternities within these families. In contrast, Families 3 and 4 exhibited a high correlated paternity, indicating that the number of trees contributing to effective pollination in these families was small.

The variation in mating system parameters was also evident in pollen flow among the mother trees as demonstrated by the high level of pollen pool heterogeneity that indicates individual mother trees sampled different pollen pools. Mother trees from Families 1, 2, 5 , and 6 had relatively low pollen pool differentiation compared to mother trees in Families 3 and 4 indicating a common pollen pool for mother trees from Families 1, 2, 5 and 6, whereas mother trees from Families 3 and 4 sampled different pollen pools.

These results indicate that the pattern of pollen dispersal in the trial was not random and mother trees from different families showed differing mating system and pollen dispersal patterns even though they are growing in the same environment and subject to the same conditions. Families 1 and 2 had high outcrossing, low to moderate biparental inbreeding and moderate correlated paternity, indicating some level of crossing between relatives and some limitation in the number of fathers per seed crop. Families 5 and 6 also had high outcrossing with some crossing between relatives but a high number of fathers per seed crop. Some level of crossing between relatives would be expected in this 
trial as mother trees within families are half-sibs. However, although crossing between relatives occurred, as expected from the trial design, the mother trees from these families shared a common pollen pool indicating effective pollen dispersal among these trees.

In contrast to the other families, Families 3 and 4 had lower outcrossing rates, crossing between relatives, a high correlation of paternity in the seed crops and sampled different pollen pools. The low outcrossing rates observed in Families 3 and 4 could result from a number of factors. Location of trees on the edge of the trial could limit opportunities for outcrossing, and low outcrossing rates could also be attributed to trees being surrounded by related individuals. However, the trial was laid out in a replicate block design with randomization of mother trees within blocks. Families 3 and 4 had internal positions within the sampled block and their position does not explain the level of inbreeding observed in these families. Variability in outcrossing rate between mother trees reflecting inherent variation in the expression of the mating system is often noted in mating studies, and this may also be an explanation for the variation in outcrossing rate observed here. However, in this study the variation is not simply an increase in selfing in these trees as other parameters of mating system also indicate restricted pollination patterns in these families compared to the others.

The most probable cause of the low outcrossing rates and restricted mating in Families 3 and 4 is a variation in flowering time compared with the other families. High inbreeding, with the addition of high crossing between relatives and correlated paternity, indicates that individuals from Families 3 and 4 were mating with only a few trees that were relatives. The similarity of progeny in mother trees from Family 3 and their spatial differentiation from other progeny in the ordination analysis also support this inference. Breeding with few related trees could occur if the flowering times of these trees were asynchronous with those of other trees in the orchard, resulting in fewer trees being available for mating and the available trees being from the same family and, consequently, related. Other observations of flowering on a few trees of $S$. spicatum in a small trial have shown variation in flowering across several months (BARRETT, 1987). Similarly, in a study of Eucalyptus marginata high correlated paternity values were explained by sporadic flowering (MILLAR et al., 2000). It has generally been found in mass flowering eucalypt species, that large variation in floral phenology among individuals appears to inhibit cross-pollination between early and late flowering trees (BURCZYK et al., 2004). This theory could also explain the moderate levels of correlated paternity in some trees of other families in this S. spicatum trial. In addition, even though mass flowering should allow multiple paternity, insect pollinators may have repetitive movements between neighboring trees that could result in a high level of correlated paternity.

This investigation indicates that $S$. spicatum is, generally, preferentially outcrossed, but is capable of selfpollination if conditions are not suitable for cross-pollination. The mean multi locus estimate $(0.885)$ is at the upper end of the range of outcrossing rates found in mass flowering species (e.g. Eucalyptus spp.), which generally have a mixed mating system of both outcrossing and selfing (MORAN and BROWN, 1980; MORAN and Bell, 1987; House and Bell, 1996). Previous studies investigating aspects of the breeding system in Santalum spp. have generally concluded that they are outcrossed. RogkHLA et al. (1997) and MCCOMB and JoNES (1998) concluded that $S$. spicatum was only capable of outcrossing, due to the presence of pre-and post-fertilisation incompatibilities that prevent selfing. Other studies (BADAMI and VenKATA RAO, 1930; MuniYAPPA et al., 1980) have reported similar results for $S$. album, and self-incompatibility, due to pollen-pistil interactions, has been observed in $S$. lanceolatum (WARBURTON et al., 2000). In contrast, successful self-pollination has been reported in other studies of S. album (SINDHU VEERENDRA and Sujatha, 1989; Sindhu VeEREndra and AdANTHA PADMANABHA, 1996), and self-compatibility was observed in S. acuminatum (SEDGELY, 1982).

The current study indicates that $S$. spicatum has a flexible reproductive strategy, including both cross- and self-pollination that is probably responsive to environmental factors such as flowering density. The lack of fertilization and seed development following self-pollination documented in other studies indicates the presence of incompatibility systems. Such systems would prevent inbreeding and should lead to very high outcrossing rates. This study supports this hypothesis, as selfincompatibility may well contribute to the complete outcrossing observed in some families where multi locus estimates of outcrossing greater than 1.00 indicated no selfing. However, trees from other families with lower outcrossing rates clearly show the capacity for selfing. The selfing identified in this study could indicate some heterogeneity in self-incompatibility systems within the species, or the breakdown of these systems in some families. Alternatively, the selfing identified here may be the result of crossing between very closely related individuals, such that the progeny produced cannot be genetically distinguished from those resulting from selfing. However this explanation is unlikely, as the loci used to genotype the progeny were highly polymorphic and all parent trees sampled had unique genotypes for these loci.

The lack of significant difference in the height of seedlings from different families indicates that there was no effect of inbreeding on seedling growth. This would be consistent with deleterious genetic interactions occurring through early incompatibility preventing fertilization and seed formation rather than through later interactions involving seedling lethal systems. Thus, while seed crops in S. spicatum generally result from outcrossing, when seed is produced following selfpollination the quality of the seed is likely to be as good as that resulting from cross pollination, at least in terms of early growth.

A previous study of genetic diversity in natural populations of S. spicatum (BYRNE et al., 2003) found moderate levels of diversity compared to other long-lived woody perennials. The levels of diversity displayed in the progeny from the Narrogin trial were similar to 
those in natural populations. The number of alleles in the natural populations was higher than that in Narrogin trial progeny but this was due to the presence of rare alleles in the natural populations. The greater effective number of alleles in the Narrogin trial progeny resulted in higher gene diversity than in the natural populations. There was a moderate level of variation between the Narrogin trial progeny and the natural populations as would be expected due to differences in allele frequencies through sampling effects. Therefore, the diversity captured in the seedlings is representative of the diversity in the semi-arid region, and the seeds produced from the trial capture the genetic diversity of the region. This diversity is also evidence that re-combinations of different alleles are occurring through cross-pollination in the trial.

A primary objective of seed orchard design is to maximize genetic diversity and outcrossing. The quality, including vigor and health, of the seed crop harvested in orchards is dependant on several factors of which the genotypic structure of the orchard and the determined mating system are the most significant (Hosius et al., 2000). Preservation of genetic diversity in forest tree seed orchards may be crucial due to the heterogenous environmental pressures trees experience over space and time (MULLER-STARCK, 1985). A primary objective for forest tree breeders is to combine maximal breeding progress in a high diversity genetic background (HosIUs et al., 2000).

The results of both the mating system and genetic diversity investigations reveal that trees in the family trial generally had high levels of outcrossing and possessed a high level of diversity that is representative of the species; despite the limited representation of families in the trial. Whilst the preferential outcrossing identified in the species indicates that seed orchards will be a successful breeding strategy for $S$. spicatum, it is important to ensure overlap in the flowering time of the chosen families. Potential variation in flowering patterns of different families is a significant factor in the design of seed orchards. The assumption of panmixis is unrealistic as flowering phenology may vary considerably. Asynchronous flowering within an orchard is potentially highly problematic since random fertilization would not occur, and this could lead to altered gene frequencies for selected traits in the seed gene pool. In addition, the effective genetic diversity of the orchard would be reduced.

Family seed orchard studies have revealed that allelic structures of progeny significantly can deviate from those of the parental generation due to desynchronized phenological flowering times. Consequently, the efficiency and viability of these seed orchards has been questioned (GOMORY et al., 2003). Further investigations of flowering patterns in different families of $S$. spicatum are essential in order to overcome the potential problems identified in this current study, and to ensure that the overall genetic composition of the seed crop is maintained. Seed orchard design should include a large number of families covering the full range of flowering times to prevent the high inbreeding rates observed in one of the families studied in this trial.

\section{Acknowledgements}

We thank Forest Products Commission for funding this study and JON BRAND for information on the trial.

\section{References}

Adams, D. R., S. Bhatnagar and R. CoOkson (1975): Sesquiterpenes of Santalum album and Santalum spicatum. Phytochemical Reports 14: 1459-1460.

Austerlitz, F. and P. Smouse (2001a): Two-Generation analysis of pollen flow across a landscape. II. Relation between $\Phi_{\mathrm{ft}}$, pollen dispersal and interfemale distance. Genetics 157: 851-857.

Austerlitz, F. and P. Smouse (2001b): Two-generation analysis of pollen flow across a landscape. III. Impact of adult population structure. Genetical Research 78: 271-280.

BADAMI, V. K. and M. G. VenKata RaO (1930): A preliminary note on the varieties of Santalum album L. in Mysore. Mysore Sandal Spike Investigation Committee Bulletin No. 1.

BARRETT, D. R. (1987): Initial observations on flowering and fruiting in Santalum spicatum (R.Br.) A.D.C. the Western Australian Sandalwood. Mulga Research Center Journal 9: 33-37.

Boland, D. J., M. Brocker, G. Chippendale, N. Hall, B. Hyland, R. Johnston, D. Kleinig and T. TurneR (1984): Forest Trees of Australia. $4^{\text {th }}$ Edition. CSIRO, Australia.

Bottin, L., A. Vaillant, P. Sire, C. Cardi and J. M. Bouvet (2005): Isolation and characterization of microsatellite loci in Santalum austrocaledonicum, Santalaceae. Molecular Ecology Notes 5: 800-802.

BRAND, J. E. (1993): Preliminary observations on ecotypic variation in Santalum spicatum 2. Genotypic variation. Mulga Research Journal 11: 13-19.

Brand, J. E., J. E. D. Fox and M. EFfEndi (1993): Variation in seed size and germination of Santalum album L. populations in NTTS Timor. Santalum 12: 37-49.

Brand, J. E., P. C. RYAN and M. R. Williams (1999): Establishment and growth of sandalwood (Santalum spicatum) in south-western Australia: the Northampton pilot trial. Australian Forestry 62: 33-37.

BuRCZYK, J., W. T. AdAMs, G. F. Moran and A. R. Griffin (2004): Complex patterns of mating revealed in a Eucalyptus regnans seed orchard using allozyme markers and the neighbourhood model. Molecular Ecology 11: 2379-2391.

Byrne, M., B. MacDonald, L. Broadhurst and J. Brand (2003): Regional genetic differentiation in Western Australia sandalwood (Santalum spicatum) as revealed by nuclear RFLP analysis. Theoretical and Applied Genetics 107: 1208-1214.

ByRne, M. (1999): High genetic identities between three oil mallee taxa, Eucalyptus kochii ssp. kochii, ssp. plenissima and $E$. horistes, based on nuclear RFLP analysis. Heredity 82: 205-211.

ByRne, M. and G. F. MoRAn (1994): Population divergence in the chloroplast genome of Eucalyptus nitens. Heredity 73: $18-28$.

DYER, R. J. (2005): GENER: a server-based analysis of pollen pool structure. Molecular Ecology Notes 5: 971-973.

Excoffier, L., P. E. Smouse and J. M. Quattro (1992): Analysis of molecular variance inferred from metric distances among DNA haplotypes: application to human mitochondrial DNA restriction data. Genetics 131: 479-491. 
Fox, J. E. D. and J. E. BRAND (1993): Preliminary observations on ecotypic variation in Santalum spicatum 1. Phenotypic variation. Mulga Research Journal 11: 1-12.

Gomory, D., R. BRUChANIK and R. LONGAUER (2003): Fertility variation and flowering asynchrony in Pinus sylvestris: consequences for the genetic structure of progeny in seed orchards. Forest Ecology and Management 274: 117-126.

Hewson, H. J. and A. S. George (1984): Flora of Australia Vol. 22. Australian Government Publishing Service, Canberra.

Hosius, B., F. Bergmann, M. Konnert and W. Henkel (2000): A concept of seed orchards based on isoenzyme gene markers. Forest Ecology and Management 131: 143-152.

House, A. P. N. and C. Bell (1996): Genetic diversity, mating system and systematic relationships in two red mahoganies, Eucalyptus pellita and E. scias. Australian Journal of Botany 44: 157-74.

JoNES, P. (2001): Sandalwood re-visited in Western Australia. Sandalwood Research Newsletter 12: 3-4.

KulKarni, R. S. and M. MuniYamma (1997): Floral biology and breeding systems in sandal, Santalum album L., pp 135-147 in Sandal and Its Products, edited by A. M. Radomiljac, H. S. Ananthapadmanabha, R. M. WelBOURNE and R. K. SATYANARAYANA, ACIAR Proceedings No. 84, Canberra.

LONERAGAN, O. W. (1990): Historical review of sandalwood (Santalum spicatum) research in Western Australia. Research Bulletin No. 4, Department of Conservation and Land Management, Perth.

McComb, J. A. and M. G. K. Jones (1998): Interspecific hybridisation between Santalum album and S. spicatum, pp. 36-41 in Sandal and Its Products, edited by A. M. Radomiljac, H. S. Ananthapadmanabha, R. M. Welbourne and R. K. SATyanarayana, ACIAR Proceedings No. 84, Canberra.

Millar, M. A., M. Byrne, D. J. Coates, M. J. C. Stukely and J. A. МсСомв (2000): Mating system studies in jarrah, Eucalyptus marginata (Myrtaceae). Australian Journal of Botany 48: 475-479.

Moran, G. F. and C. Bell (1987): The origin and genetic diversity of Pinus radiata in Australia. Theoretical and Applied Genetics 73: 616-22.

Moran, G. F. and A. H. D. Brown (1980): Temporal heterogeneity of outcrossing rates in alpine ash (Eucalyptus delegatensis R. T. Bak.). Theoretical and Applied Genetics 57: 101-105.

Moran, G. F., P. A. Butcher and J. C. Glaubitz (2000): Application of genetic markers in the domestication, conservation and utilisation of genetic resources of Australasian tree species. Australian Journal of Botany 4: 313-320.

MULLER-STARCK, G. (1985): Reproductive success of genotypes of Pinus sylvestris L. in different environments, pp 118-33 in Population Genetics in Forestry, edited by H. R. Gregorius, Springer-Verlag, Berlin Heidelberg.
Muniyappa, V., N. Vijayakumar, M. Subbarao and K. A. KushalaPPA (1980): Studies on Sandal spike disease in the forests of Karnataka State. Bangalore, UAS, GKVK Part 1.

Peakall, R., P. E. Smouse and H. R. Duff (1995): Evolutionary implications of allozyme and RAPD variation in diploid populations of Buffalograss (Buchloe dachyloides Nutt. Engelm.). Molecular Ecology 4: 135-147.

PEAKALL, R. and P. E. SMOUSE (2001): GenAlEx5: Genetic Analysis in Excel. Population genetic software for teaching and research. The Australian National University, Canberra, Australia. http://www.anu.edu.au/BoZo/ GenAlEx/.

RAI, S. N. (1990): Status and cultivation of sandalwood in India, pp 66-71 in Sandalwood in the Pacific, edited by L. HAMILTON and C. E. ConRAD, USDA Forest Service Technical Report PSW-122.

RITLAND, K. (2002): Extensions of models for the estimation of mating systems using the $\mathrm{n}$ independent loci. Heredity 88: 221-228.

RugkhlA, A., J. A. McComb and M. G. K Jones (1997): Intra- and inter-specific pollination of Santalum spicatum and S. album. Australian Journal of Botany 45: 1083-1985.

SEDGELY, M. (1982): Floral anatomy and pollen tube growth in the Quandong (Santalum acuminatum R.Br. A.DC.). Australian Journal of Botany 30: 601-609.

Shea, S. R., A. M. Radomiljac, J. Brand and P. Jones (1998): An overview of sandalwood and the development of sandal in farm forestry in Western Australia, pp 9-15 in Sandal and Its Products, edited by A. M. RADOMILJAC, H. S. ANANTJAPADMANABHa, R. M. Welbourne and R. K. SATYANARAYANA, ACIAR Proceedings No. 84, Canberra.

Sindhu VeERENDRA, H. C. and ANANThA PADMANABHA (1996): The breeding system in sandal (Santalum album L.). Silvae Genetica 45: 188-190.

Sindhu Veerendra, H. C. and M. Sujatha (1989): Pollination studies in Santalum album L. Current Science 58: 629-630.

Smouse, P. E., R. J. Dyer, R. D. Westfall and V. L. Sork (2001): Two-generation analysis of pollen flow across a landscape I: male gamete heterogeneity among females. Evolution 55: 260-271.

SRinivasan, V. V., V. R. Sivaramakrishnan, C. R. RanGASWAMY, H. S. ANANTHAPADMANABHA and $\mathrm{K}$. $\mathrm{H}$. SHANKARANARAYANA (1992): Sandal (Santalum album L.). Indian Council of Forestry Research and Education, Dehra Dun.

Warburton, C. L., E. James, Y. J. Fripp, S. J. Trueman and H. M. WALlACE (2000): Clonality and sexual reproductive failure in remnant populations of Santalum lanceolatum (Santalaceae). Biological Conservation 96: 45-54. 